\title{
The Current State of Pediatric Acute Respiratory Distress Syndrome
}

\author{
Kirsten E. Orloff, MD, David A. Turner, MD, FCCM, FCCP, and Kyle J. Rehder, MD, FCCM, FCCP
}

Pediatric acute respiratory distress syndrome (PARDS) is a significant cause of morbidity and mortality in children. Children with PARDS often require intensive care admission and mechanical ventilation. Unfortunately, beyond lung protective ventilation, there are limited data to support our management strategies in PARDS. The Pediatric Acute Lung Injury Consensus Conference (PALICC) offered a new definition of PARDS in 2015 that has improved our understanding of the true epidemiology and heterogeneity of the disease as well as risk stratification. Further studies will be crucial to determine optimal management for varying disease severity. This review will present the physiologic basis of PARDS, describe the unique pediatric definition and risk stratification, and summarize the current evidence for current standards of care as well as adjunctive therapies.

Keywords: pediatric, acute respiratory distress syndrome, Pediatric Acute Lung Injury Consensus Conference, lung protective ventilation, oxygenation index, acute hypoxemic respiratory failure

\section{Introduction}

A CUTE RESPIRATORY DISTRESS syndrome (ARDS) is a clinical syndrome caused by disruption of the alveolar epithelial-endothelial permeability barrier unrelated to cardiogenic pulmonary edema. ${ }^{1}$ Injury may occur directly to the alveolar epithelium (ie, pneumonia, inhaled toxins, etc.) or indirectly to the capillary endothelium secondary to systemic inflammation as seen in conditions such as sepsis or pancreatitis. ${ }^{1}$ Disruption of the alveolar endothelial barrier leads to accumulation of protein-rich fluid in the alveoli. $^{2}$ Dysregulated inflammation and coagulation then ensue, resulting in impaired lymphatic drainage and surfactant degradation. ${ }^{2}$ Clinically, these alveolar changes result in a restrictive lung disease characterized by hypoxemia, radiographic opacities, decreased functional residual capacity, increased physiologic dead space, and decreased lung compliance. ${ }^{1}$ Resolution of the inflammation usually occurs after several weeks, with potential development of fibrosis. ${ }^{3}$ The most common cause of ARDS in children is viral respiratory infection, although ARDS can be associated with many other underlying conditions, including pneumonia, sepsis, trauma, burns, pancreatitis, inhalation, transfusion, and cardiopulmonary bypass. ${ }^{2}$

\section{Defining Pediatric Acute Respiratory Distress Syndrome}

Historically, characterization of acute lung injury (ALI) or ARDS in children was based on adult definitions determined by the 1994 American-European Consensus Conference (AECC) and the subsequent 2012 Berlin definition. ${ }^{4-6}$ Recognizing that ARDS in children is different than adults, an international panel of experts convened the Pediatric Acute Lung Injury Consensus Conference (PALICC) to establish new definitions and guidelines for pediatric acute respiratory distress syndrome (PARDS). ${ }^{4}$ The 2015 PALICC definition broadens the radiographic requirement to include any new parenchymal infiltrate(s). ${ }^{4}$ Additional key differences in the PARDS definition include allowing use of pulse oximetry to avoid underestimating ARDS prevalence in children if arterial blood oxygenation measurements are not available and $\mathrm{SpO}_{2} \leq 97 \%$, and utilization of the oxygenation index (OI) $\left[\left(\mathrm{FiO}_{2} \times\right.\right.$ mean airway pressure $\left.\left.\times 100\right) / \mathrm{PaO}_{2}\right]$ and oxygenation saturation index $(\mathrm{OSI})\left[\left(\mathrm{FiO}_{2} \times\right.\right.$ mean airway pressure $\left.\times 100\right) /$ $\mathrm{SpO}_{2}$ ] rather than the $\mathrm{PaO}_{2} / \mathrm{FiO}_{2}(\mathrm{P} / \mathrm{F})$ ratio to assess hypoxemia $^{4}$ (Table 1). Integration of OI into the definition accounts for variability in ventilator support when categorizing lung disease.

Division of Pediatric Critical Care Medicine, Department of Pediatrics, Duke Children's Hospital, Durham, North Carolina.

(C) Orloff et al. 2019; Published by Mary Ann Liebert, Inc. This Open Access article is distributed under the terms of the Creative Commons Attribution Noncommercial License (http://creativecommons.org/licenses/by-nc/4.0/) which permits any noncommercial use, distribution, and reproduction in any medium, provided the original author(s) and the source are cited. 
TABle 1. PARD CRiteria (PALICC Guidelines)

\section{PARDS baseline criteria ${ }^{\mathrm{a}}$}

Acute onset; within 7 days of clinical insult

Chest imaging (radiograph or computed tomography) findings of new infiltrates (unilateral or bilateral) consistent with acute parenchymal disease

Edema not fully explained by fluid overload or cardiac failure

May present as new acute lung disease in setting of chronic lung disease and/or heart disease

Exclusions

Perinatal lung disease

PARDS severity stratification

\begin{tabular}{llccc}
\hline & \multicolumn{1}{c}{ At-risk } & Mild & Moderate & Severe \\
\hline OI & $<4$ with $\mathrm{O}_{2}$ supplementation required to keep $\mathrm{SpO}_{2}>88 \%$ & $4 \leq 8$ & $8 \leq 16$ & $\geq 16$ \\
OSI & $<5$ with $\mathrm{O}_{2}$ supplementation required to keep $\mathrm{SpO}_{2}>88 \%$ & $5 \leq 7.5$ & $7.5 \leq 12.3$ & $\geq 12.3$ \\
\hline
\end{tabular}

Special considerations

Noninvasive ventilation

PARDS: P/F ratio $\leq 300$ or $\mathrm{SpO}_{2} / \mathrm{FiO}_{2}$ ratio $\leq 264$ on full face-mask noninvasive ventilation with minimum CPAP/EPAP $\geq 5 \mathrm{~cm} \mathrm{H} \mathrm{H}_{2} \mathrm{O}$ (no severity stratification)

At-risk: requiring $\mathrm{FiO}_{2} \geq 40 \%$ to attain $\mathrm{SpO}_{2} 88 \%-92 \%$ with nasal mask CPAP/BiPAP or requiring age-based oxygen flow rate via mask or nasal cannula to maintain $\mathrm{SpO}_{2} 88 \%-97 \%$

$<1$ Year: $2 \mathrm{~L} / \mathrm{min}$

1-5 Years: $4 \mathrm{~L} / \mathrm{min}$

5-10 Years: $6 \mathrm{~L} / \mathrm{min}$

$>10$ Years: $8 \mathrm{~L} / \mathrm{min}$

Cyanotic heart disease: no specific OI or OSI cutoff; PARDS definition based on clinician determined "new-onset hypoxemia" in patient meeting other baseline criteria

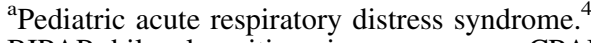

BIPAP, bilevel positive airway pressure; CPAP, continuous positive airway pressure; EPAP, expiratory positive airway pressure; OI, oxygenation index; OSI, oxygenation saturation index; PALICC, Pediatric Acute Lung Injury Consensus Conference; PARDS, pediatric acute respiratory distress syndrome; $\mathrm{P} / \mathrm{F}, \mathrm{PaO}_{2} / \mathrm{FiO}_{2}$.

The PALICC criteria were recently compared to prior definitions (Berlin, AECC) in 2 studies of pediatric patients in the intensive care unit (ICU). ${ }^{7,8}$ Both studies concluded that the new criteria identified a higher number of PARDS patients. In addition, when compared to Berlin and AECC definitions, patients meeting PALICC criteria for PARDS were found to have a lower overall mortality rate ${ }^{7}$ and a lower proportion of severe ARDS and complications. ${ }^{8}$ Even more recently, the prospective international Pediatric Acute Respiratory Distress Syndrome Incidence and Epidemiology (PARDIE) study, the largest PARDS study using the PALICC definition, demonstrated in over 700 children that the PALICC definition identified more children as having PARDS than the Berlin definition. ${ }^{9}$ Notably, capturing more patients with milder forms of PARDS with the broader definition may have serious implications on future outcome studies if they are not stratified by disease severity.

\section{Epidemiology, Mortality, and Risk Stratification}

Respiratory failure is the most common cause of death for children admitted to pediatric intensive care units (PICUs), ${ }^{10}$ and ARDS accounts for $1 \%-10 \%$ of PICU admissions. ${ }^{7,811}$ Mortality rates in PARDS are highly variable across studies, likely attributable to varying comorbid conditions and different etiologies. ${ }^{11}$ A meta-analysis by Wong et al. found the pooled mortality rate in PARDS to be $\sim 24 \%$, with an overall downtrend in mortality over the last 3 decades. ${ }^{12}$ This trend likely reflects earlier awareness and diagnosis ${ }^{12}$ improved ventilation strategies, and changes in general ICU care. ${ }^{11}$ The PARDIE study was the first to discriminate mortality risk by PARDS severity as defined by PALICC, demonstrating a significant, stepwise increase in mortality with increasing disease severity (10\%-15\% for mild or moderate PARDS versus 33\% for severe PARDS). ${ }^{9}$ Measured OI at $6-12 \mathrm{~h}$ and at $24 \mathrm{~h}$ after onset of PARDS has been found to more accurately stratify degree of lung injury than prognostication at onset. ${ }^{13,14}$ The PARDIE study corroborated this finding, revealing that PARDS severity level at $6 \mathrm{~h}$ was more predictive of ICU mortality than Berlin ARDS severity groups. ${ }^{9}$

Cause of death in PARDS is variable, given the heterogenous etiology of the disease process. In a large retrospective study, neurologic failure and multisystem organ failure were the primary causes of early and late deaths, respectively, and only a minority of deaths were attributed to refractory hypoxemia. ${ }^{15}$ Significant predictors of mortality include immunocompromised state, multiorgan dysfunction, older age, and severity of hypoxemia. ${ }^{11,16}$ A recent prospective cohort study demonstrated similar outcomes for direct and indirect PARDS, whereas infectious PARDS was associated with lower severity of illness and mortality compared with noninfectious PARDS. ${ }^{17}$ Moreover, immunocompromised state, a well-described predictor of mortality in ARDS, was not found to be associated with mortality in noninfectious PARDS. ${ }^{17}$

Overall, PARDS mortality has decreased in the last few decades and is lower than adult ARDS mortality, which ranges from $35 \%$ to $46 \%$ with mild to severe. ${ }^{18}$ However, PARDS mortality remains significant, and improvements in identification, risk stratification, and targeted management will be crucial to further reduce the mortality burden.

\section{Standards of Care}

This section provides a review of the current best practice strategies for the management of PARDS. These 
Table 2. Current Evidence and Recommendations for Pediatric Acute Respiratory DISTRESS SYNDROME THERAPIES

\begin{tabular}{|c|c|c|c|}
\hline Therapy & Evidence & PALICC recommendation & References \\
\hline $\begin{array}{l}\text { Lung-protective } \\
\text { ventilation }\end{array}$ & $\begin{array}{l}\text { Decreased mortality and more } \\
\text { ventilator-free days with low } \\
\text { tidal volumes and limited } \\
\text { plateau pressure in adult } \\
\text { ARDS (RCT). }\end{array}$ & $\begin{array}{l}\text { Low tidal volumes } \\
3-6 \mathrm{~mL} / \mathrm{kg} \text { if poor compliance } \\
5-8 \mathrm{~mL} / \mathrm{kg} \text { if preserved } \\
\text { compliance } \\
\mathrm{P}_{\text {plateau }} \leq 28 \mathrm{~cm} \mathrm{H}_{2} \mathrm{O} \\
\text { Permissive hypoxemia } \\
\text { Mild PARDS: } 92 \%-97 \% \\
\text { Severe PARDS: } 88 \%-92 \% \text { and } \\
\text { PEEP > } 10 \mathrm{~cm} \mathrm{H}_{2} \mathrm{O} \\
\text { Permissive hypercapnia } \\
\text { Moderate/severe: pH } 7.15-7.30 \text {, } \\
\text { with exceptions for certain } \\
\text { populations. }\end{array}$ & $\begin{array}{l}\text { ARDS Network } \\
(2000)^{22} ; \text { Rimensberger }^{20} \\
\text { and Cheifetz }\end{array}$ \\
\hline Fluid management & $\begin{array}{l}\text { Conservative fluid management } \\
\text { improved lung function, } \\
\text { decreased duration of MV } \\
\text { and ICU LOS in adult } \\
\text { ARDS. No mortality } \\
\text { difference (RCT). } \\
\text { Observational pediatric } \\
\text { studies favor conservative } \\
\text { approach. }\end{array}$ & $\begin{array}{l}\text { After initial resuscitation, use a } \\
\text { goal-directed fluid management } \\
\text { protocol to maintain intravascular } \\
\text { volume while minimizing fluid } \\
\text { overload. }\end{array}$ & $\begin{array}{l}\text { National Heart, Lung, } \\
\text { and Blood Institute } \\
\text { Acute Respiratory } \\
\text { Distress Syndrome } \\
\text { (ARDS) Clinical Trials } \\
\text { Network et al., } \\
\text { Flori et al., } \\
\text { Valentine et al. }{ }^{34} \\
\text { Valentine et al. }\end{array}$ \\
\hline Sedation & $\begin{array}{l}\text { Sedation protocol decreased } \\
\text { sedation exposure without } \\
\text { effect on MV duration or } \\
\text { long-term outcomes in } \\
\text { pediatric respiratory failure } \\
\text { (RCT). }\end{array}$ & $\begin{array}{l}\text { Targeted sedation to ensure patients } \\
\text { can tolerate MV to optimize } \\
\text { oxygen delivery/consumption. } \\
\text { Pain and sedation scales to titrate } \\
\text { sedation per a goal-directed } \\
\text { protocol. }\end{array}$ & $\begin{array}{l}\text { Curley et al., } \\
\quad \text { Valentine et al. }\end{array}$ \\
\hline HFOV & $\begin{array}{l}\text { No benefit, potential harm in } \\
\text { adult ARDS (RCTs). Small } \\
\text { pediatric RCTs and } \\
\text { observational studies show } \\
\text { improved oxygenation but no } \\
\text { difference in mortality, } \\
\text { duration of MV, or LOS. } \\
\text { PROSpect (pediatric RCT) } \\
\text { is ongoing. }\end{array}$ & $\begin{array}{l}\text { Consider HFOV in patients with } \\
\text { moderate to severe PARDS and } \\
\mathrm{P}_{\text {plateau }}>28 \mathrm{~cm} \mathrm{H}_{2} \mathrm{O} \text {. }\end{array}$ & $\begin{array}{l}\text { Rimensberger and } \\
\text { Cheifetz, }{ }^{20} \text { El-Nawawy } \\
\text { et al., }{ }^{29} \text { Ferguson et al., } \\
\text { Young et al., }{ }^{42} \text { Arnold } \\
\text { et al., }{ }^{43} \text { Gupta et al., } \\
\text { Bateman et al., } \\
\text { Qiao et al. }\end{array}$ \\
\hline Prone positioning & $\begin{array}{l}\text { 50\% Mortality reduction in } \\
\text { severe ARDS (single RCT). } \\
\text { Adult systematic reviews } \\
\text { report improved oxygenation, } \\
\text { safe, potential mortality } \\
\text { reduction when coupled with } \\
\text { other lung protective } \\
\text { strategies. Pediatric RCT } \\
\text { supports safety but no } \\
\text { difference in outcomes. } \\
\text { PROSpect is ongoing. }\end{array}$ & $\begin{array}{l}\text { Consider prone positioning as an } \\
\text { option in cases of severe PARDS. } \\
\text { Cannot recommend its use as a } \\
\text { routine therapy given current } \\
\text { pediatric data. }\end{array}$ & $\begin{array}{l}\text { Curley et al.. }{ }_{51}^{27} \text { Curley, } \\
\text { Sud et al., } \\
\text { Guerin et al., } \\
\text { Tamburro and } \\
\text { Kneyber }^{53}\end{array}$ \\
\hline $\begin{array}{l}\text { Recruitment } \\
\text { maneuvers }\end{array}$ & $\begin{array}{l}\text { Sustained inflation improves } \\
\text { oxygenation in adults with } \\
\text { higher lung compliance and } \\
\text { incremental PEEP titration is } \\
\text { safe and improved } \\
\text { oxygenation in ARDS and } \\
\text { PARDS. No data on } \\
\text { mortality or morbidity. }\end{array}$ & $\begin{array}{l}\text { Careful incremental titration of } \\
\text { PEEP. }\end{array}$ & $\begin{array}{l}\text { Rimensberger and } \\
\text { Cheifetz, } \\
\text { Grasso et al.. } 54 \\
\text { Cruces et al. } 55 \\
\text { Povoa et al. }{ }^{56}\end{array}$ \\
\hline NMB & $\begin{array}{l}\text { Adult studies support NMB use } \\
\text { in early severe ARDS. } \\
\text { Pediatric observational study } \\
\text { demonstrates NMB improved } \\
\text { oxygenation. }\end{array}$ & $\begin{array}{l}\text { Consider NMB if sedation alone is } \\
\text { inadequate to achieve effective } \\
\text { MV. Target minimal effective } \\
\text { dose. }\end{array}$ & $\begin{array}{l}\text { Valentine et al., } \\
\text { Gainnier et al. }{ }^{35} \\
\text { Forel et al., } \\
\text { Papazian et al. } 59 \\
\text { Murray et al., }{ }^{50} \\
\text { Wilsterman et al. }{ }^{62}\end{array}$ \\
\hline
\end{tabular}


TABle 2. (CONTINUED)

\begin{tabular}{|c|c|c|c|}
\hline Therapy & Evidence & PALICC recommendation & References \\
\hline Nitric oxide & $\begin{array}{l}\text { Pediatric RCTs, meta-analysis, } \\
\text { and retrospective data all } \\
\text { report improved oxygenation } \\
\text { with no impact on mortality. }\end{array}$ & $\begin{array}{l}\text { Cannot recommend routine use of } \\
\text { iNO. Consider in patients with } \\
\text { known pulmonary hypertension, } \\
\text { severe right ventricular } \\
\text { dysfunction, or as bridge to } \\
\text { ECMO. }\end{array}$ & $\begin{array}{l}\text { Tamburro and Kneyber, } \\
\text { Day et al., }{ }^{53} \text { Dobyns } \\
\text { et al., }{ }^{64} \text { Ibrahim et al., } \\
\text { Afshari et al.66 } \\
\text { Bhalla et al. }{ }^{63}\end{array}$ \\
\hline Surfactant & $\begin{array}{l}\text { Large pediatric RCTs with } \\
\text { mixed data; overall improved } \\
\text { oxygenation but no difference } \\
\text { in duration of MV, LOS } \\
\text { or mortality. }\end{array}$ & $\begin{array}{l}\text { Do not recommend routine use of } \\
\text { surfactant. Need further studies in } \\
\text { specific populations. }\end{array}$ & $\begin{array}{l}\text { Tamburro and Kneyber, }{ }^{53} \\
\text { Willson et al., }{ }^{72} \text { Willson } \\
\text { et al., }{ }^{73} \text { Thomas et al., } \\
\text { Thomas et al. }{ }^{75}\end{array}$ \\
\hline Steroids & $\begin{array}{l}\text { Mixed data in adult ARDS. } \\
\text { Small pediatric RCT found } \\
\text { that methylprednisolone had } \\
\text { no difference in mortality, } \\
\text { duration of MV, LOS. } \\
\text { Observational pediatric data } \\
\text { demonstrate longer duration } \\
\text { of MV with corticosteroids } \\
>24 \mathrm{~h} \text {. }\end{array}$ & $\begin{array}{l}\text { Do not recommend corticosteroids } \\
\text { as routine therapy. Need further } \\
\text { studies in specific populations. }\end{array}$ & $\begin{array}{l}\text { Tamburro and } \\
\text { Kneyber, }{ }^{53} \text { Peter et al., } \\
\text { Tang et al., } \\
\text { Meduri et al. }{ }^{78} \\
\text { Drago et al., } \\
\text { Yehya et al. }\end{array}$ \\
\hline ECMO & $\begin{array}{l}\text { Strong evidence in neonates. } \\
\text { Recent adult RCTs show } \\
\text { potential mortality benefit. } \\
\text { No pediatric RCTs. }\end{array}$ & $\begin{array}{l}\text { Consider ECMO in severe PARDS } \\
\text { when lung-protective strategies } \\
\text { result in inadequate gas } \\
\text { exchange, after serial evaluations } \\
\text { demonstrate deteriorating trend. } \\
\text { Disease process must be deemed } \\
\text { reversible or lung transplant a } \\
\text { suitable treatment. }\end{array}$ & $\begin{array}{l}\text { Refer to Extracorporeal } \\
\text { Membrane Oxygenation } \\
\text { section of the article for } \\
\text { full list of neonatal } \\
\text { references, Peek et al., } \\
\text { Combes et al., } \\
\text { Dalton and Macrae } \\
\text { D9 }\end{array}$ \\
\hline
\end{tabular}

ARDS, acute respiratory distress syndrome; ECMO, extracorporeal membrane oxygenation; HFOV, high-frequency oscillatory ventilation; ICU, intensive care unit; iNO, inhaled nitric oxide; LOS, length of stay; MV, mechanical ventilation; NMB, neuromuscular blockade; PEEP, positive-end-expiratory pressure; PROSpect, PRone and OScillation Pediatric Clinical Trial; RCT, randomized controlled trial.

recommendations, along with those for adjunctive therapies covered in the following section, are summarized in Table 2.

\section{Lung-protective ventilation}

The goals of ARDS management are to treat the underlying cause, provide adequate oxygenation and ventilation, and protect the lungs from ventilator-induced lung injury (VILI). The aims of lung-protective ventilation are to avoid overdistension (volutrauma and barotrauma), minimize the cyclic opening and closing of alveoli (atelectrauma), ${ }^{19,20}$ and minimize injurious effects of biochemical mediators on the lung and distal organs (biotrauma). ${ }^{21}$

There are no randomized controlled trials (RCTs) outlining optimal ventilator mode or strategy in PARDS. Thus, pediatric intensivists have relied on the landmark ARDS Network trial evaluating adults with ALI and ARDS, which found that mechanical ventilation with lower tidal volume $(6 \mathrm{~mL} / \mathrm{kg}$ compared to $12 \mathrm{~mL} / \mathrm{kg}$ ) and limited plateau pressure $\left(30 \mathrm{~cm} \mathrm{H}_{2} \mathrm{O}\right)$ resulted in decreased mortality and more ventilator-free days. ${ }^{22}$ Standard of care for mechanical ventilation in the PICU is generally consistent with the ARDS Network study, and the PALICC guidelines recommend tidal volumes of 3-6 and 5-8 mL/kg for patients with poor and more preserved respiratory compliance, respectively, along with limiting inspiratory plateau pressure to $28 \mathrm{~cm} \mathrm{H}_{2} \mathrm{O} .{ }^{20} \mathrm{Of}$ note, some observational pediatric studies demonstrate decreased mortality ${ }^{16}$ and more ventilator-free days ${ }^{23}$ with higher tidal volumes, although the significance of these findings is not clear. These findings led to weak agreement among the PALICC group regarding tidal volume targets, but targets remain generally consistent with currently available lung protective tidal volume goals. These data do suggest that the physiology and risk for VILI may be different in children when compared with adults, and a pediatric RCT is needed to better inform the optimal tidal volume strategy in children before routine deviation from current standards.

Another important component of conventional mechanical ventilation (CMV) in ARDS is positive-end-expiratory pressure (PEEP). PEEP creates an open lung strategy by preventing lung collapse and atelectotrauma caused by reopening collapsed alveoli with each breath cycle. ${ }^{20}$ Two meta-analyses in adults with ARDS indicate that higher PEEP is associated with lower hospital mortality. ${ }^{20,24,25} \mathrm{~A}$ recent pediatric multicenter retrospective study by Khemani et al. also demonstrated that PEEP levels lower than the ARDS Network model were associated with higher mortality. ${ }^{26}$ PALICC strongly recommends the use of PEEP up to $15 \mathrm{~cm} \mathrm{H}_{2} \mathrm{O}$ or greater for severe PARDS. ${ }^{20}$

To minimize the potential toxicity of ventilatory support required to oxygenate and ventilate PARDS patients, permissive hypoxemia and hypercapnia should be considered. Given that improved oxygenation has not been shown to improve outcomes, ${ }^{22,27-29}$ PALICC recommends oxygen saturation goals of $92 \%-97 \%$ for mild PARDS and $88 \%-92 \%$ and $\mathrm{PEEP}>10 \mathrm{~cm} \mathrm{H}_{2} \mathrm{O}$ for severe PARDS. ${ }^{20}$ In patients 
whose oxygen saturation is maintained $<92 \%$, it is important to follow markers of oxygen delivery, such as central venous saturation. $^{20}$ Further PALICC recommendations include considering permissive hypercapnia for moderate to severe PARDS to minimize VILI, maintaining pH 7.15-7.30 using lung-protective strategies. ${ }^{20}$ Laboratory data have demonstrated that hypercapnic acidosis itself-not simply as the manifestation of low tidal volume ventilation - may attenuate VILI, further supporting this strategy. ${ }^{30,31}$ While most populations will tolerate permissive hypercapnia and acidosis, these guidelines should be avoided in patients with intracranial hypertension, severe pulmonary hypertension, certain congenital heart disease lesions, hemodynamic instability, and significant ventricular dysfunction. ${ }^{20}$

\section{Fluid management}

To date, no pediatric RCTs have investigated fluid management strategies in PARDS. Two opposing strategies exist: (1) fluid resuscitation to maintain adequate cardiac output and extrapulmonary organ function in the setting of widespread inflammation and (2) fluid restriction to minimize pulmonary edema. ${ }^{32}$ The multicentered, randomized Fluid and Catheter Treatment Trial (FACTT) comparing conservative versus liberal fluid management strategies for adults with ARDS favored the conservative approach, as it improved lung function, shortened duration of mechanical ventilation, and reduced ICU stay without increasing extrapulmonary organ failure. ${ }^{32}$ However, there was no mortality difference between the 2 groups.

Several observational studies have evaluated fluid management in pediatric ARDS and ALI. In 2011, a post hoc analysis of an observational study suggested that positive fluid balance was associated with increased mortality and prolonged mechanical ventilation, independent of multisystem organ failure and severity of hypoxemia. ${ }^{33}$ More recently, Valentine et al. applied a Bayesian statistical approach based on the FACTT findings to a multicenter observational pediatric study. ${ }^{34}$ Similar to previous studies, the authors demonstrated an inverse relationship between positive cumulative fluid balance and ventilator-free days, even after adjusting for illness severity. ${ }^{34}$ These studies highlight the need for a prospective study of conservative fluid management in children with PARDS.

PALICC recommendations reflect the need to balance end-organ function with the development of pulmonary edema. After initial resuscitation, PALICC recommends a goal-directed fluid management protocol to maintain intravascular volume while minimizing fluid overload. ${ }^{35}$

\section{Sedation}

Adequate sedation of the mechanically ventilated child will ideally optimize patient safety and respiratory support while providing analgesia and anxiolysis to maintain the child in a calm but responsive state. ${ }^{35}$ Until recently, sedatives have been used extensively in mechanically ventilated pediatric patients without high-quality evidence to guide clinical practice. ${ }^{36,37}$ The Randomized Evaluation of Sedation Titration fOr Respiratory failurE (RESTORE) trial evaluated a nurse-driven sedation protocol in 2,900 mechanically ventilated children across 31 PICUs. ${ }^{38}$ The authors found no reduction in duration of mechanical ventilation with the sedation protocol compared to usual care in children with acute respiratory failure, but did note a more wakeful state and lower exposure to sedative medications. ${ }^{38}$ Long-term follow-up demonstrated no difference in functional status or mental health risk between treatment arms. ${ }^{39}$

The PALICC recommendations align with this strategy, supporting targeted sedation to ensure that patients can tolerate mechanical ventilation to optimize oxygen delivery, oxygen consumption, and work of breathing. ${ }^{35}$ Further recommendations include the use of pain and sedation scales to monitor and titrate sedation per a goal-directed protocol, frequent interprofessional communication to define goals, and an individualized sedation weaning plan guided by objective withdrawal assessment. ${ }^{35}$ There remains a need for additional investigations on the impact of pharmacogenetics and critical illness, as well as the risks of neurotoxicity, immunomodulation, sleep cycle disruption, and delirium associated with sedation. ${ }^{40}$

\section{Adjunctive Therapies}

\section{High-frequency ventilation}

When CMV fails, high-frequency oscillatory ventilation (HFOV) is often used as a "rescue" strategy for refractory hypoxemia. HFOV utilizes higher mean airway pressures in conjunction with lower than physiologic tidal volumes at extremely high rates, with the goal of minimizing VILI and improving gas exchange through an open-lung strategy.

Early studies of HFOV in adults were promising, but limited by small sample size and outdated ventilatory strategies. ${ }^{41}$ Two recent adult RCTs, Oscillation for Acute Respiratory Distress Syndrome Treated Early (OSCILLATE) ${ }^{41}$ and High Frequency Oscillation in ARDS (OSCAR), ${ }^{42}$ suggest no benefit and potential harm associated with HFOV. The OSCILLATE trial reported higher mortality and increased use of vasopressors, sedation, and neuromuscular blockage in the HFOV group. The OSCAR trial found no significant difference in mortality between adult ARDS patients supported with HFOV compared to CMV. ${ }^{42}$ These studies remain controversial due to methodological concerns, and their applicability to PARDS is unclear.

Although a 1994 RCT showed potential benefit from early HFOV use in pediatric respiratory failure, subsequent pediatric studies have demonstrated no clear benefit with HFOV. ${ }^{43}$ A recent retrospective, observational administrative database study of $>9,000$ children with acute respiratory failure found longer duration of mechanical ventilation and higher mortality associated with HFOV compared with CMV. ${ }^{44}$ A secondary propensity score analysis of RESTORE study data also demonstrated increased ventilator days with no mortality difference with early HFOV use compared to CMV and/or late HFOV. ${ }^{45}$ More recently, a Turkish RCT of 200 children with PARDS found that HFOV improved oxygenation but showed no difference in mortality, duration of mechanical ventilation, or length of stay (LOS), compared to CMV. ${ }^{29}$ Consistent with other studies, the most common cause of death was multiorgan dysfunction rather than refractory hypoxemia. A metaanalysis of 6 RCTs with a total of 246 PARDS patients also demonstrated improved oxygenation with no significant difference in mortality or duration of mechanical ventilation. ${ }^{46}$ Despite these investigations evaluating $\mathrm{HFOV}$ in pediatric ARDS, definitive data are lacking, and many 
experts agree that HFOV continues to have a role in the management of severe respiratory failure. It is hoped that the ongoing PRone and OScillation Pediatric Clinical Trial $\left(\right.$ PROSpect) ${ }^{47}$ will provide needed clarity. PALICC recommendations include consideration of HFOV in patients with moderate to severe PARDS and elevated plateau pressures $\left(>28 \mathrm{~cm} \mathrm{H}_{2} \mathrm{O}\right){ }^{20}$

\section{Prone positioning}

Prone positioning was introduced in the 1970s as a method to improve lung mechanics and oxygenation in mechanically ventilated patients. Its efficacy and safety in ARDS have been studied extensively over the last 2 decades, primarily in adults. A 1999 systematic review of 20 clinical studies representing 297 adult and pediatric patients found improved oxygenation after prone positioning with rare adverse events. ${ }^{48}$

Three recent meta-analyses have assessed the impact of prone positioning on mortality in adults with ARDS, with varying results. The initial meta-analysis in 2008 assessed 13 studies, totaling $>1,500$ adult and pediatric patients, and found prone positioning to improve oxygenation without significant effect on mortality. ${ }^{49}$ A follow-up study of 10 trials demonstrated that prone positioning was associated with decreased mortality only in severe ARDS (P/F ratio $<100 \mathrm{mHg}){ }^{50}$ The most recent meta-analysis in 2014 of 11 RCTs found a significant reduction in ARDS mortality with prone positioning when coupled with lung protective ventilation. ${ }^{51}$ This metaanalysis included the Proning Severe ARDS Patients (PROSEVA) study, which reported a $50 \%$ mortality reduction with prone positioning in adults with severe ARDS. ${ }^{52}$

Unlike many other management strategies in ARDS, a multicenter RCT evaluating prone positioning in pediatrics is available ${ }^{27}$ and demonstrated proning to be safe, but found no difference in duration of mechanical ventilation, mortality, or other health outcomes. ${ }^{27}$ The ongoing PROSpect study hopes to better determine its efficacy in severe PARDS. ${ }^{47}$ The PALICC guidelines recommend considering prone positioning as an option in cases of severe PARDS, but cannot recommend its use as a routine therapy in PARDS given the current pediatric data. ${ }^{53}$

\section{Recruitment maneuvers}

Recruitment maneuvers involve utilizing increased PEEP or sustained inflation to reopen regions of lung collapse. Adult studies have demonstrated that sustained inflation or high levels of PEEP more successfully improve oxygenation in patients with higher lung compliance, such as those with early ARDS with atelectasis or inflammatory edema, compared to those with decreased chest wall compliance. ${ }^{20,54}$ However, predicting which patients may respond to lung recruitment may be difficult, and there are no data demonstrating the impact of recruitment maneuvers on outcomes such as mortality or duration of mechanical ventilation. There is also concern that sustained inflation may preferentially deliver pressure to lungs units that are already open, causing heterogeneous overdistension. Thus, PALICC recommends more measured recruitment through careful incremental titration of PEEP, which has been shown to be safe and effective in improving oxygenation in both adult and pediatric ARDS, rather than sustained inflation maneuvers. ${ }^{20,55,56}$

\section{Neuromuscular blockade}

Neuromuscular blockade (NMB) is an important adjunct to sedation for mechanically ventilated patients to achieve optimal oxygen delivery and lung mechanics. However, a paucity of high-quality evidence exists to guide use of NMB in mechanically ventilated children. Adult clinical trials and guidelines support NMB use in adults with early severe ARDS. ${ }^{57-60}$ Of note, these studies have evaluated cisatricurium, while aminosteroids (ie, rocuronium, vecuronium) have been found to have a higher risk of myopathy and neuropathy and potentially deserve separate investigation. ${ }^{61}$ To date, no RCTs have evaluated the utility of NMB in children with PARDS. A prospective physiologic study by Wilsterman et al. showed improved OI in pediatric patients with acute hypoxemic respiratory failure who received continuous NMB during mechanical ventilation. ${ }^{62}$ Based largely on the available adult data, PALICC recommends considering NMB in children with PARDS if sedation alone is inadequate to achieve effective mechanical ventilation, targeting the minimal effective dose. ${ }^{35}$

\section{Nitric oxide}

Nitric oxide (NO) is produced in the vascular endothelium and causes relaxation of smooth muscle. Inhaled NO (iNO) has been used as a pulmonary vasodilator to increase blood flow to areas with adequate ventilation, thus improving ventilation/perfusion mismatch and oxygenation in diseases such as ARDS. ${ }^{53}$ Three RCTs in children with PARDS have demonstrated transient improvement in oxygenation with iNO, although these investigations were not designed to study mortality. ${ }^{63-65}$ A meta-analysis of 14 RCTs studying the effect of iNO in $>1,300$ adults and children with ALI and ARDS again found transient improvement in oxygenation but no reduction in mortality. ${ }^{66}$ Consistent with those findings, a recent retrospective cohort study of nearly 500 children with PARDS also demonstrated no improvement in either mortality or ventilator-free days with iNO. ${ }^{67}$ Given iNO has not been shown to improve patient outcomes in PARDS, PALICC does not recommend its routine use. ${ }^{53}$ However, the guidelines suggest considering iNO in patients with known pulmonary hypertension, severe right ventricular dysfunction, or as a bridge to extracorporeal life support in severe cases.

\section{Surfactant}

Surfactant dysfunction is part of the known pathophysiology of ARDS, and surfactant replacement has had great success in infantile respiratory distress syndrome. However, pediatric clinical trials of surfactant replacement have not demonstrated a clear improvement in outcomes outside of the neonatal population. An uncontrolled trial in 1996 of calf lung surfactant (calfactant) in 29 children with acute hypoxic respiratory failure demonstrated improvement in oxygenation and ability to wean ventilatory support with calfactant administration. ${ }^{68}$ Two subsequent studies of porcine surfactant (curosurf) in infants with bronchiolitis demonstrated improved oxygenation, decreased duration of mechanical ventilation, and decreased ICU LOS with exogenous surfactant. ${ }^{69,70}$ Mortality was not assessed as there were no deaths in either trial. Willson et al. then conducted a prospective RCT that demonstrated the use of calfactant in 
children with acute hypoxic respiratory failure was associated with similar findings of improved oxygenation and decreased length of ventilation and ICU stay, with no difference in mortality. ${ }^{71}$

Subsequent larger studies demonstrate mixed results. A multicenter RCT of calfactant use in $>150$ infants and children with respiratory failure again demonstrated improved oxygenation, but no difference in duration of ventilation or LOS. ${ }^{72}$ The study found a reduction in mortality with calfactant, which became nonsignificant after post hoc adjustment for immunodeficiency. Subsequent trials of calfactant in direct-injury PARDS and PARDS following stem cell transplant and lucinactant for PARDS demonstrated no benefit for outcomes such as mortality, ventilation time, or LOS. $^{73-75}$ Given these data, the PALICC guidelines do not recommend routine use of surfactant in PARDS, ${ }^{53}$ but recommend further studies to determine if other specific populations may benefit.

\section{Steroids}

Dysregulated inflammation occurring in $\mathrm{ARDS}^{2}$ has prompted interest in use of steroids as an anti-inflammatory treatment. Systematic reviews of studies of adults with ARDS demonstrate mixed results. ${ }^{76,77}$ A 2018 meta-analysis by Meduri et al. evaluating 9 RCTs of low-to-moderate dose prolonged glucocorticoid treatment in adult ARDS reported moderate-to-high evidence that steroid therapy is safe and reduces duration of mechanical ventilation, ICU and overall LOS, and mortality. ${ }^{78}$ A small pediatric pilot RCT investigating the use of methylprednisolone in PARDS found no difference in mortality, duration of mechanical ventilation, ICU LOS, or overall LOS with steroid therapy. ${ }^{79}$ A larger observational PARDS study found fewer ventilator-free days and longer duration of mechanical ventilation with corticosteroid exposure $>24 \mathrm{~h}^{80}$ Given the lack of clear evidence in pediatrics, PALICC recommends against corticosteroids as routine therapy in PARDS pending further studies in specific populations. ${ }^{53}$

\section{Extracorporeal membrane oxygenation}

Successes with extracorporeal membrane oxygenation (ECMO) in severe neonatal respiratory failure ${ }^{81-85}$ have led to its use in children and adults. In PARDS, ECMO can augment systemic oxygen delivery to allow the injured lungs to rest and recover. However, ECMO carries significant risk and requires substantial resources and expertise. The international Extracorporeal Life Support Organization (ELSO) registry contains data on nearly 60,000 patients supported with ECMO. ${ }^{86}$ Over the last decade, there has been exponential growth of ECMO utilization in adults with severe respiratory failure. ${ }^{87}$ The Conventional Ventilation or ECMO for Severe Adult Respiratory Failure (CESAR) trial in adults found that ECMO was cost-effective and increased 6-month disability-free survival. ${ }^{87}$ However, the recent ECMO to Rescue Lung Injury in Severe ARDS (EOLIA) trial showed no significant difference in 60-day mortality in adults with severe ARDS supported with ECMO when compared to CMV. ${ }^{88}$

Unfortunately, despite strong evidence in neonates ${ }^{81-85}$ and potential benefit in adults, ${ }^{87,88}$ clinical trial evidence for ECMO use in PARDS is lacking. Despite this lack of definitive data, ECMO use in children increased substantially from 2009 to $2015,{ }^{86}$ with a $50 \%$ increase in the number of centers reporting pediatric ECMO cases to the ELSO registry and a $24 \%$ annual increase in pediatric ECMO cases over that time period. ${ }^{86}$ Survival to hospital discharge for children with respiratory failure supported with ECMO is $60 \%$, with variable outcome based on etiology. ${ }^{86}$ PALICC guidelines suggest that ECMO should be considered in severe PARDS when toxic support is needed to maintain gas exchange. ${ }^{89}$ However, ECMO should only be considered after serial evaluations demonstrate deteriorating trends and if the disease process is deemed reversible or if lung transplant is a suitable treatment. ${ }^{89}$

\section{Next Steps}

Despite the importance of PARDS as a substantial source of pediatric morbidity and mortality, high-quality data around potential treatments are lacking, which limits our understanding of which therapies lead to optimal outcomes in our PARDS patients. Not surprisingly, this paucity of definitive evidence has led to significant PARDS management variability across centers. A 2013 survey of 59 centers across 12 countries demonstrated that adjunctive therapies are commonly utilized in clinical scenarios consistent with PARDS. ${ }^{90}$ More than $80 \%$ of respondents reported that they would use iNO, three-quarters would prone patients, and around half would consider exogenous surfactant, despite a lack of evidence to support the efficacy of these adjuncts.

The ongoing PROSpect ${ }^{47}$ hopes to provide clarity around 2 adjunct therapies, prone positioning and HFOV. This phase III clinical trial (UG3 HL141736-01) aims to enroll 1,000 severe PARDS patients at more than 50 international centers. Additional work in PARDS is also underway investigating biomarkers that may better stratify mortality risk and identify targeted treatments for future clinical trials. ${ }^{91-94}$ Beyond these investigations, there remain robust opportunities for prospective study of the effect of various treatment strategies on outcomes in PARDS, including but not limited to ventilatory modes (including airway pressure release ventilation, high-frequency jet ventilation, and neutrally adjusted ventilator assist) and strategies, fluid management, NMB, surfactant in specific populations, steroids, and ECMO.

Prior clinical trials have focused on all children with ARDS, which many experts suggest is the reason for negative trials. Children with mild to moderate PARDS have a relatively low mortality, and the inclusion of these children in large trials may dilute the potential treatment benefit that might exist in more severely ill patients. Recent adult investigations suggest a focus on patients with severe ARDS may increase the likelihood to demonstrate a positive treatment effect. ${ }^{52,59,88,95}$

There also remains a great need for outcomes data in PARDS, particularly relating to morbidity. In adult survivors of ARDS, highly morbid effects include decreased lung function, reduced quality of life, and decreased neurocognitive functioning. ${ }^{11}$ Similar studies are warranted in the pediatric population, as physical and neurocognitive development may be even more greatly impacted. The cumulative consequence of these morbidities on an individual and on society is another opportunity for investigation. As noted above, stratifying outcome studies by disease severity will be ever more important with the broadened definition of PARDS introduced in 2015. 
PARDS remains a disease process with significant morbidity and mortality. However, with improved understanding of its epidemiology and heterogeneity in the last decade, as well as ever-growing gains in risk stratification, the future is ripe with opportunity for more tailored clinical trials to determine best treatment strategies and improve outcomes.

\section{Author Disclosure Statement}

No competing financial interests exist.

\section{References}

1. Sapru A, Flori H, Quasney MW, et al. Pathobiology of acute respiratory distress syndrome. Pediatr Crit Care Med 2015; 16:S6-S22.

2. Heidemann SM, Nair A, Bulut Y, et al. Pathophysiology and management of acute respiratory distress syndrome in children. Pediatr Clin North Am 2017; 64:1017-1037.

3. Matthay MA, Zemans RL. The acute respiratory distress syndrome: pathogenesis and treatment. Annu Rev Pathol 2011; 6:147-163.

4. Pediatric acute respiratory distress syndrome: consensus recommendations from the Pediatric Acute Lung Injury Consensus Conference. Pediatr Crit Care Med 2015; 16:428-439.

5. Bernard GR, Artigas A, Brigham KL, et al. The AmericanEuropean Consensus Conference on ARDS. Definitions, mechanisms, relevant outcomes, and clinical trial coordination. Am J Respir Crit Care Med 1994; 149:818-824.

6. Force ADT, Ranieri VM, Rubenfeld GD, et al. Acute respiratory distress syndrome: the Berlin definition. JAMA 2012; 307:2526-2533.

7. Parvathaneni K, Belani S, Leung D, et al. Evaluating the performance of the Pediatric Acute Lung Injury Consensus Conference definition of acute respiratory distress syndrome. Pediatr Crit Care Med 2017; 18:17-25.

8. Gupta S, Sankar J, Lodha R, et al. Comparison of prevalence and outcomes of pediatric acute respiratory distress syndrome using Pediatric Acute Lung Injury Consensus Conference criteria and Berlin definition. Front Pediatr 2018; 6:93.

9. Khemani RG, Smith L, Lopez-Fernandez YM, et al. Paediatric acute respiratory distress syndrome incidence and epidemiology (PARDIE): an international, observational study. Lancet Respir Med 2018; 7:115-128.

10. Burns JP, Sellers DE, Meyer EC, et al. Epidemiology of death in the PICU at five U.S. teaching hospitals. Crit Care Med 2014; 42:2101-2108.

11. Quasney MW, Lopez-Fernandez YM, Santschi M, et al. The outcomes of children with pediatric acute respiratory distress syndrome: proceedings from the Pediatric Acute Lung Injury Consensus Conference. Pediatr Crit Care Med 2015; 16:S118-S131.

12. Wong JJ, Jit M, Sultana R, et al. Mortality in pediatric acute respiratory distress syndrome: a systematic review and meta-analysis. J Intensive Care Med 2017. [Epub ahead of print]; DOI: 10.1177/0885066617705109.

13. Yehya N, Servaes S, Thomas NJ. Characterizing degree of lung injury in pediatric acute respiratory distress syndrome. Crit Care Med 2015; 43:937-946.

14. Yehya N, Thomas NJ, Khemani RG. Risk stratification using oxygenation in the first 24 hours of pediatric acute respiratory distress syndrome. Crit Care Med 2018; 46:619-624.

15. Dowell JC, Parvathaneni K, Thomas NJ, et al. Epidemiology of cause of death in pediatric acute respiratory distress syndrome. Crit Care Med 2018; 46:1811-1819.
16. Erickson $\mathrm{S}$, Schibler A, Numa A, et al. Acute lung injury in pediatric intensive care in Australia and New Zealand: a prospective, multicenter, observational study. Pediatr Crit Care Med 2007; 8:317-323.

17. Yehya N, Keim G, Thomas NJ. Subtypes of pediatric acute respiratory distress syndrome have different predictors of mortality. Intensive Care Med 2018; 44:1230-1239.

18. Bellani G, Laffey JG, Pham T, et al. Epidemiology, patterns of care, and mortality for patients with acute respiratory distress syndrome in intensive care units in 50 countries. JAMA 2016; 315:788-800.

19. Dreyfuss D, Saumon G. Ventilator-induced lung injury: lessons from experimental studies. Am J Respir Crit Care Med 1998; 157:294-323.

20. Rimensberger PC, Cheifetz IM. Ventilatory support in children with pediatric acute respiratory distress syndrome: proceedings from the Pediatric Acute Lung Injury Consensus Conference. Pediatr Crit Care Med 2015; 16:S51-S60.

21. Curley GF, Laffey JG, Zhang H, et al. Biotrauma and ventilator-induced lung injury: clinical implications. Chest 2016; 150:1109-1117.

22. Acute Respiratory Distress Syndrome Network, Brower RG, Matthay MA, et al. Ventilation with lower tidal volumes as compared with traditional tidal volumes for acute lung injury and the acute respiratory distress syndrome. N Engl J Med 2000; 342:1301-1308.

23. Khemani RG, Conti D, Alonzo TA, et al. Effect of tidal volume in children with acute hypoxemic respiratory failure. Intensive Care Med 2009; 35:1428-1437.

24. Phoenix SI, Paravastu S, Columb M, et al. Does a higher positive end expiratory pressure decrease mortality in acute respiratory distress syndrome? A systematic review and meta-analysis. Anesthesiology 2009; 110:1098-1105.

25. Briel M, Meade M, Mercat A, et al. Higher vs lower positive end-expiratory pressure in patients with acute lung injury and acute respiratory distress syndrome: systematic review and meta-analysis. JAMA 2010; 303:865-873.

26. Khemani RG, Parvathaneni K, Yehya N, et al. Positive endexpiratory pressure lower than the ARDS network protocol is associated with higher pediatric acute respiratory distress syndrome mortality. Am J Respir Crit Care Med 2018; 198 : 77-89.

27. Curley MA, Hibberd PL, Fineman LD, et al. Effect of prone positioning on clinical outcomes in children with acute lung injury: a randomized controlled trial. JAMA 2005; 294:229-237.

28. Dobyns EL, Anas NG, Fortenberry JD, et al. Interactive effects of high-frequency oscillatory ventilation and inhaled nitric oxide in acute hypoxemic respiratory failure in pediatrics. Crit Care Med 2002; 30:2425-2429.

29. El-Nawawy A, Moustafa A, Heshmat H, et al. High frequency oscillatory ventilation versus conventional mechanical ventilation in pediatric acute respiratory distress syndrome: a randomized controlled study. Turk J Pediatr 2017; 59:130-143.

30. Contreras M, Ansari B, Curley G, et al. Hypercapnic acidosis attenuates ventilation-induced lung injury by a nuclear factor-kappaB-dependent mechanism. Crit Care Med 2012; 40:2622-2630.

31. Horie S, Ansari B, Masterson C, et al. Hypercapnic acidosis attenuates pulmonary epithelial stretch-induced injury via inhibition of the canonical NF-kappaB pathway. Intensive Care Med Exp 2016; 4:8.

32. National Heart, Lung, and Blood Institute Acute Respiratory Distress Syndrome (ARDS) Clinical Trials Net- 
work, Wiedemann HP, Wheeler AP, et al. Comparison of two fluid-management strategies in acute lung injury. N Engl J Med 2006; 354:2564-2575.

33. Flori HR, Church G, Liu KD, et al. Positive fluid balance is associated with higher mortality and prolonged mechanical ventilation in pediatric patients with acute lung injury. Crit Care Res Pract 2011; 2011:854142.

34. Valentine SL, Sapru A, Higgerson RA, et al. Fluid balance in critically ill children with acute lung injury. Crit Care Med 2012; 40:2883-2889.

35. Valentine SL, Nadkarni VM, Curley MA. Nonpulmonary treatments for pediatric acute respiratory distress syndrome: proceedings from the Pediatric Acute Lung Injury Consensus Conference. Pediatr Crit Care Med 2015; 16:S73-S85.

36. Hartman ME, McCrory DC, Schulman SR. Efficacy of sedation regimens to facilitate mechanical ventilation in the pediatric intensive care unit: a systematic review. Pediatr Crit Care Med 2009; 10:246-255.

37. Playfor S, Jenkins I, Boyles C, et al. Consensus guidelines on sedation and analgesia in critically ill children. Intensive Care Med 2006; 32:1125-1136.

38. Curley MA, Wypij D, Watson RS, et al. Protocolized sedation vs usual care in pediatric patients mechanically ventilated for acute respiratory failure: a randomized clinical trial. JAMA 2015; 313:379-389.

39. Watson RS, Asaro LA, Hertzog JH, et al. Long-term outcomes after protocolized sedation versus usual care in ventilated pediatric patients. Am J Respir Crit Care Med 2018; 197:1457-1467.

40. Zuppa AF, Curley MAQ. Sedation analgesia and neuromuscular blockade in pediatric critical care: overview and current landscape. Pediatr Clin North Am 2017; 64:1103-1116.

41. Ferguson ND, Cook DJ, Guyatt GH, et al. High-frequency oscillation in early acute respiratory distress syndrome. N Engl J Med 2013; 368:795-805.

42. Young D, Lamb SE, Shah S, et al. High-frequency oscillation for acute respiratory distress syndrome. N Engl J Med 2013; 368:806-813.

43. Arnold JH, Hanson JH, Toro-Figuero LO, et al. Prospective, randomized comparison of high-frequency oscillatory ventilation and conventional mechanical ventilation in pediatric respiratory failure. Crit Care Med 1994; 22:1530-1539.

44. Gupta P, Green JW, Tang X, et al. Comparison of highfrequency oscillatory ventilation and conventional mechanical ventilation in pediatric respiratory failure. JAMA Pediatr 2014; 168:243-249.

45. Bateman ST, Borasino S, Asaro LA, et al. Early highfrequency oscillatory ventilation in pediatric acute respiratory failure. A propensity score analysis. Am J Respir Crit Care Med 2016; 193:495-503.

46. Qiao JY, Li YZ, Wang HY, et al. A meta analysis of the efficacy of high-frequency oscillatory ventilation versus conventional mechanical ventilation for treating pediatric acute respiratory distress syndrome [in Chinese]. Zhongguo Dang Dai Er Ke Za Zhi 2017; 19:430-435.

47. The PRone and OScillation Pediatric Clinical Trial (PROSpect). 2018. www.prospect-network.org. Accessed January 17, 2019.

48. Curley MA. Prone positioning of patients with acute respiratory distress syndrome: a systematic review. Am J Crit Care 1999; 8:397-405.

49. Sud S, Sud M, Friedrich JO, et al. Effect of mechanical ventilation in the prone position on clinical outcomes in patients with acute hypoxemic respiratory failure: a systematic review and meta-analysis. CMAJ 2008; 178:1153-1161.
50. Sud S, Friedrich JO, Taccone P, et al. Prone ventilation reduces mortality in patients with acute respiratory failure and severe hypoxemia: systematic review and metaanalysis. Intensive Care Med 2010; 36:585-599.

51. Sud S, Friedrich JO, Adhikari NK, et al. Effect of prone positioning during mechanical ventilation on mortality among patients with acute respiratory distress syndrome: a systematic review and meta-analysis. CMAJ 2014; 186: E381-E390.

52. Guerin C, Reignier J, Richard JC, et al. Prone positioning in severe acute respiratory distress syndrome. N Engl J Med 2013; 368:2159-2168.

53. Tamburro RF, Kneyber MC. Pulmonary specific ancillary treatment for pediatric acute respiratory distress syndrome: proceedings from the Pediatric Acute Lung Injury Consensus Conference. Pediatr Crit Care Med 2015; 16:S61S72.

54. Grasso S, Mascia L, Del Turco M, et al. Effects of recruiting maneuvers in patients with acute respiratory distress syndrome ventilated with protective ventilatory strategy. Anesthesiology 2002; 96:795-802.

55. Cruces P, Donoso A, Valenzuela J, et al. Respiratory and hemodynamic effects of a stepwise lung recruitment maneuver in pediatric ARDS: a feasibility study. Pediatr Pulmonol 2013; 48:1135-1143.

56. Povoa P, Almeida E, Fernandes A, et al. Evaluation of a recruitment maneuver with positive inspiratory pressure and high PEEP in patients with severe ARDS. Acta Anaesthesiol Scand 2004; 48:287-293.

57. Gainnier M, Roch A, Forel JM, et al. Effect of neuromuscular blocking agents on gas exchange in patients presenting with acute respiratory distress syndrome. Crit Care Med 2004; 32:113-119.

58. Forel JM, Roch A, Marin V, et al. Neuromuscular blocking agents decrease inflammatory response in patients presenting with acute respiratory distress syndrome. Crit Care Med 2006; 34:2749-2757.

59. Papazian L, Forel JM, Gacouin A, et al. Neuromuscular blockers in early acute respiratory distress syndrome. N Engl J Med 2010; 363:1107-1116.

60. Murray MJ, DeBlock H, Erstad B, et al. Clinical practice guidelines for sustained neuromuscular blockade in the adult critically ill patient. Crit Care Med 2016; 44:2079_ 2103.

61. Price D, Kenyon NJ, Stollenwerk N. A fresh look at paralytics in the critically ill: real promise and real concern. Ann Intensive Care 2012; 2:43.

62. Wilsterman MEF, de Jager P, Blokpoel R, et al. Short-term effects of neuromuscular blockade on global and regional lung mechanics, oxygenation and ventilation in pediatric acute hypoxemic respiratory failure. Ann Intensive Care 2016; 6:103.

63. Day RW, Allen EM, Witte MK. A randomized, controlled study of the 1-hour and 24-hour effects of inhaled nitric oxide therapy in children with acute hypoxemic respiratory failure. Chest 1997; 112:1324-1331.

64. Dobyns EL, Cornfield DN, Anas NG, et al. Multicenter randomized controlled trial of the effects of inhaled nitric oxide therapy on gas exchange in children with acute hypoxemic respiratory failure. J Pediatr 1999; 134:406412.

65. Ibrahim TS, El-Mohamady HS. Inhaled nitric oxide and prone position: how far they can improve oxygenation in pediatric patients with acute respiratory distress syndrome? J Med Sci 2007; 7:390-395. 
66. Afshari A, Brok J, Moller AM, et al. Inhaled nitric oxide for acute respiratory distress syndrome and acute lung injury in adults and children: a systematic review with metaanalysis and trial sequential analysis. Anesth Analg 2011; 112:1411-1421.

67. Bhalla AK, Yehya N, Mack WJ, et al. The association between inhaled nitric oxide treatment and ICU mortality and 28-day ventilator-free days in pediatric acute respiratory distress syndrome. Crit Care Med 2018; 46:1803-1810.

68. Willson DF, Jiao JH, Bauman LA, et al. Calf's lung surfactant extract in acute hypoxemic respiratory failure in children. Crit Care Med 1996; 24:1316-1322.

69. Luchetti M, Casiraghi G, Valsecchi R, et al. Porcinederived surfactant treatment of severe bronchiolitis. Acta Anaesthesiol Scand 1998; 42:805-810.

70. Luchetti M, Ferrero F, Gallini C, et al. Multicenter, randomized, controlled study of porcine surfactant in severe respiratory syncytial virus-induced respiratory failure. Pediatr Crit Care Med 2002; 3:261-268.

71. Willson DF, Zaritsky A, Bauman LA, et al. Instillation of calf lung surfactant extract (calfactant) is beneficial in pediatric acute hypoxemic respiratory failure. Members of the Mid-Atlantic Pediatric Critical Care Network. Crit Care Med 1999; 27:188-195.

72. Willson DF, Thomas NJ, Markovitz BP, et al. Effect of exogenous surfactant (calfactant) in pediatric acute lung injury: a randomized controlled trial. JAMA 2005; 293: 470-476.

73. Willson DF, Thomas NJ, Tamburro R, et al. Pediatric calfactant in acute respiratory distress syndrome trial. Pediatr Crit Care Med 2013; 14:657-665.

74. Thomas NJ, Guardia CG, Moya FR, et al. A pilot, randomized, controlled clinical trial of lucinactant, a peptidecontaining synthetic surfactant, in infants with acute hypoxemic respiratory failure. Pediatr Crit Care Med 2012; 13: 646-653.

75. Thomas NJ, Spear D, Wasserman E, et al. CALIPSO: a randomized controlled trial of calfactant for acute lung injury in pediatric stem cell and oncology patients. Biol Blood Marrow Transplant 2018; 24:2479-2486.

76. Peter JV, John P, Graham PL, et al. Corticosteroids in the prevention and treatment of acute respiratory distress syndrome (ARDS) in adults: meta-analysis. BMJ 2008; 336: 1006-1009.

77. Tang BM, Craig JC, Eslick GD, et al. Use of corticosteroids in acute lung injury and acute respiratory distress syndrome: a systematic review and meta-analysis. Crit Care Med 2009; 37:1594-1603.

78. Meduri GU, Siemieniuk RAC, Ness RA, et al. Prolonged low-dose methylprednisolone treatment is highly effective in reducing duration of mechanical ventilation and mortality in patients with ARDS. J Intensive Care 2018; 6:53.

79. Drago BB, Kimura D, Rovnaghi CR, et al. Double-blind, placebo-controlled pilot randomized trial of methylprednisolone infusion in pediatric acute respiratory distress syndrome. Pediatr Crit Care Med 2015; 16:e74-e81.

80. Yehya N, Servaes S, Thomas NJ, et al. Corticosteroid exposure in pediatric acute respiratory distress syndrome. Intensive Care Med 2015; 41:1658-1666.

81. Bartlett RH, Roloff DW, Cornell RG, et al. Extracorporeal circulation in neonatal respiratory failure: a prospective randomized study. Pediatrics 1985; 76:479-487.

82. O'Rourke PP, Crone RK, Vacanti JP, et al. Extracorporeal membrane oxygenation and conventional medical therapy in neonates with persistent pulmonary hypertension of the newborn: a prospective randomized study. Pediatrics 1989; 84:957-963.

83. Bifano EM, Hakanson DO, Hingre RV, et al. Prospective randomized controlled trial of conventional treatment or transport for ECMO in infants with persistent pulmonary hypertension (PPHN) [abstract]. Pediatr Res 1992; 31:196A.

84. UK collaborative randomised trial of neonatal extracorporeal membrane oxygenation. UK Collaborative ECMO Trail Group. Lancet 1996; 348:75-82.

85. Mugford M, Elbourne D, Field D. Extracorporeal membrane oxygenation for severe respiratory failure in newborn infants. Cochrane Database Syst Rev 2008; 3:CD001340.

86. Barbaro RP, Paden ML, Guner YS, et al. Pediatric Extracorporeal Life Support Organization registry international report 2016. ASAIO J 2017; 63:456-463.

87. Peek GJ, Mugford M, Tiruvoipati R, et al. Efficacy and economic assessment of conventional ventilatory support versus extracorporeal membrane oxygenation for severe adult respiratory failure (CESAR): a multicentre randomised controlled trial. Lancet 2009; 374:1351-1363.

88. Combes A, Hajage D, Capellier G, et al. Extracorporeal membrane oxygenation for severe acute respiratory distress syndrome. N Engl J Med 2018; 378:1965-1975.

89. Dalton HJ, Macrae DJ. Extracorporeal support in children with pediatric acute respiratory distress syndrome: proceedings from the Pediatric Acute Lung Injury Consensus Conference. Pediatr Crit Care Med 2015; 16:S111-S117.

90. Santschi M, Randolph AG, Rimensberger PC, et al. Mechanical ventilation strategies in children with acute lung injury: a survey on stated practice pattern. Pediatr Crit Care Med 2013; 14:e332-e337.

91. Dahmer MK, Quasney MW, Sapru A, et al. Interleukin-1 receptor antagonist is associated with pediatric acute respiratory distress syndrome and worse outcomes in children with acute respiratory failure. Pediatr Crit Care Med 2018; 19:930-938.

92. Sapru A, Liu KD, Wiemels J, et al. Association of common genetic variation in the protein $\mathrm{C}$ pathway genes with clinical outcomes in acute respiratory distress syndrome. Crit Care 2016; 20:151.

93. Yehya N, Wong HR. Adaptation of a biomarker-based sepsis mortality risk stratification tool for pediatric acute respiratory distress syndrome. Crit Care Med 2018; 46:e9-e16.

94. Zinter MS, Orwoll BE, Spicer AC, et al. Incorporating inflammation into mortality risk in pediatric acute respiratory distress syndrome. Crit Care Med 2017; 45:858-866.

95. Writing Group for the Alveolar Recruitment for Acute Respiratory Distress Syndrome Trial (ART) Investigators, Cavalcanti AB, Suzumura EA, et al. Effect of lung recruitment and titrated positive end-expiratory pressure (PEEP) vs low PEEP on mortality in patients with acute respiratory distress syndrome: a randomized clinical trial. JAMA 2017; 318:1335-1345.

Address correspondence to:
Kirsten E. Orloff, MD
Division of Pediatric Critical Care Medicine
Department of Pediatrics
Duke Children's Hospital
DUMC Box 3046
Durham, NC 27710

E-mail: kirsten.orloff@duke.edu

Received for publication January 18, 2019; accepted after revision March 24, 2019. 